\title{
Patientin mit Adnextorsion
}

\author{
Andreas D. Ebert, Matthias David
}

\section{Anamnese, Symptome und Klinik \\ $\nabla$}

Die 36-jährige, bereits per laparoskopischer suprazervikaler Hysterektomie (LASH) therapierte Patientin wurde in den frühen Morgenstunden mit akut einsetzenden, betont linksseitigen Unterbauchschmerzen nach Geschlechtsverkehr in einer externen chirurgischen Klinik aufgenommen. Da dort keine Frauenklinik vorhanden war, erfolgte auch keine gynäkologische Untersuchung. Die Behandlung der „nicht schlimmer werdenden“ Unterbauchschmerzen erfolgte bei negativem Serum- $\beta$-HCG „konservativ" mit Schmerzmedikamenten sowie der Einleitung einer Antibiotikatherapie. Am 1. Tag nach Beginn der Symptome wurde eine Computertomografie durchgeführt, die einen „Unterbauchtumor links“ ergab. Am 2. Tag nach Beginn der Symptome wurde die Patientin wegen eines „gynäkologischen“ Unterbauchtumors links in die Klinik verlegt.

\section{Diagnostik/Differenzialdiagnose \\ $\nabla$}

Die gynäkologische Untersuchung ergab einen zystisch-dolenten Adnexbefund links, der vaginalsonografisch bestätigt wurde. Die Anamnese war wegweisend. Unter der klinischen und sonografischen Verdachtsdiagnose einer abgelaufenen „Stieldrehung“ erfolgte hier die sofortige Laparoskopie.

\section{Therapie und weiterführende Betreuung $\nabla$}

Bei dezenter Leukozytose und CRP-Anstieg erfolgten die perioperative Antibiotikaprophylaxe mit Cefazolin sowie eine Thromboseprophylaxe mit Enoxaparin. Laparoskopisch musste die Adnexektomie durchgeführt werden, da bei dem vorliegenden „verschleppten" Befund eine effektive Detorquierung nicht mehr möglich war ( $\boldsymbol{A}$ Abb. 1 a bis $\mathbf{f}$ ). Nach ausführlicher laparoskopischer Bauchtoilette wegen des bereits vorliegenden Hämatoperi-
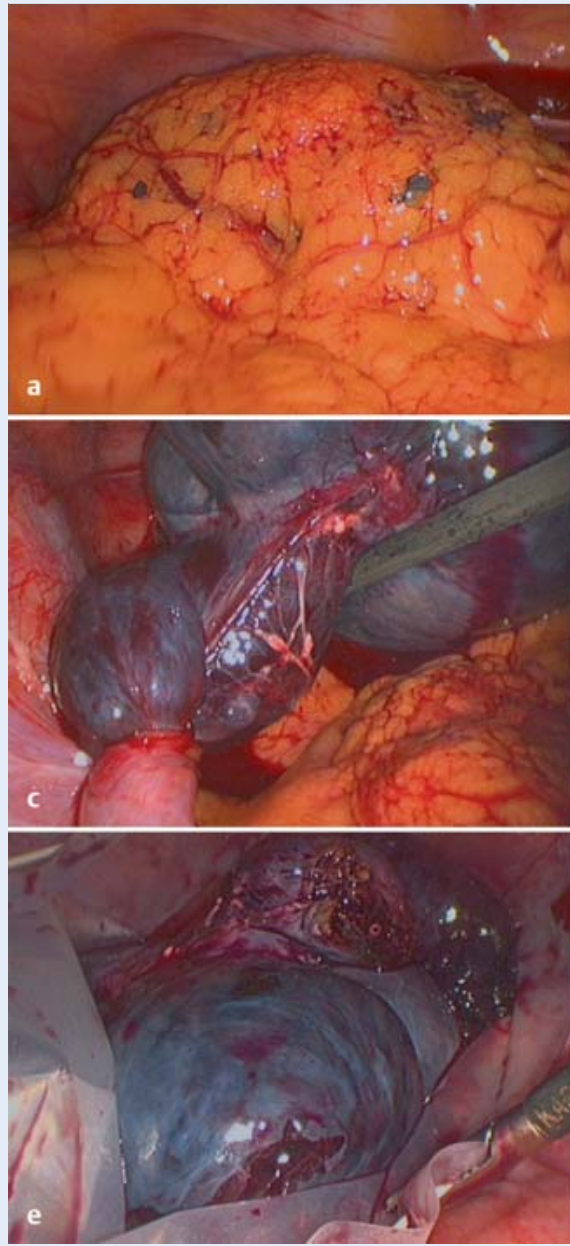
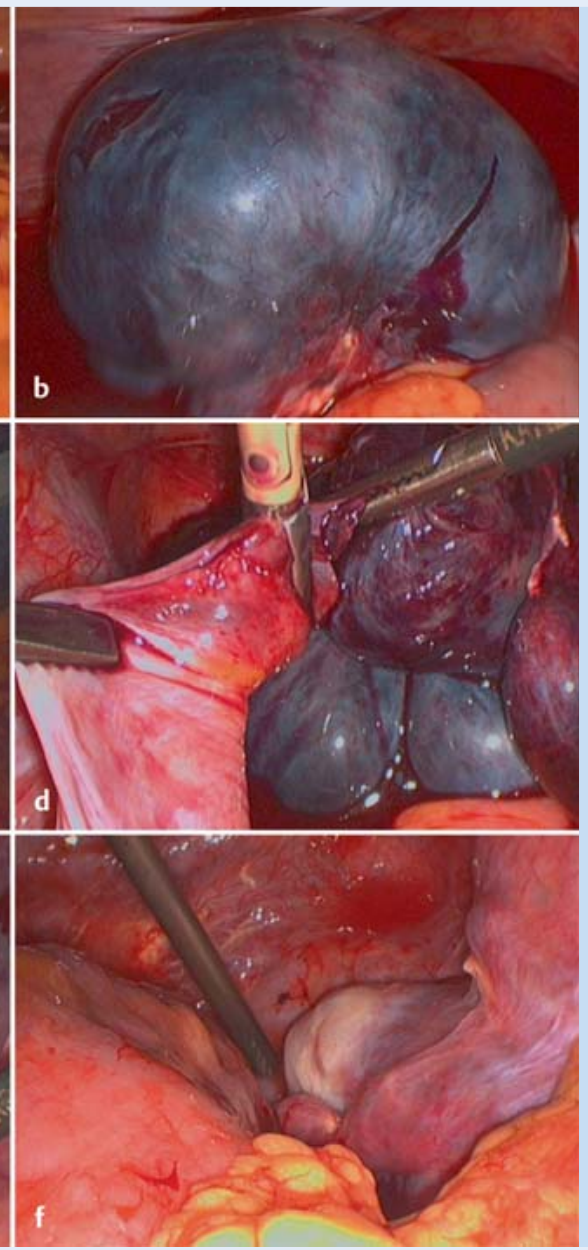

Abb. 1 a bis $\mathbf{f}$ Die Verdachtsdiagnose einer Stieldrehung wurde bestätigt. Es lag bereits ein Hämatoperitoneum vor (a). Die Adnexe waren schon nekrotisch und konnten nicht mehr detorquiert werden (b, c). Die linken Adnexe wurden über bipolare Overholt-Klemme und Schere in sicherer Distanz zum linken Ureter abgesetzt, in einen Bergesack platziert und aus dem Bauchraum entfernt (c-e). Die kontralaterale Tube zeigte keinen pathologischen Befund (f). Die histopathologische Untersuchung bestätigte die komplette Nekrose der linken Tube und des Ovars, also den Organverlust. 
toneums erfolgte die Adhäsionsprophylaxe mit Icodextrin-Lösung. Die Entlassung der Patientin in die Betreuung des Facharztes bei objektivem und subjektivem Wohlbefinden war am 2. postoperativen Tag möglich.

\section{Konsequenz}

Wenn Sie an eine Stieldrehung denken, muss unverzüglich operativ gehandelt werden. Es droht immer der Organverlust!

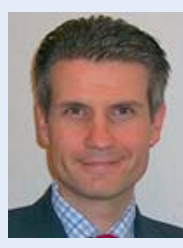

Korrespondenz

Prof. Dr. med. Matthias David

Charité - Universitätsmedizin Berlin, Campus Virchow-Klinikum

matthias.david@charite.de

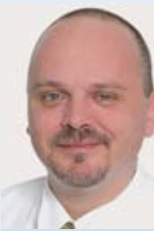

Korrespondenz

Prof. Dr. med. Dr. phil. Dr. h.c. mult. Andreas D. Ebert

Praxis für Frauengesundheit, Gynäkologie und Geburtshilfe, Berlin

info@prof-ebert.de 